\title{
Marko Paşa: İki Biyografiye Sığmayan Bir Efsane
}

\section{Marco Pasha: A Myth Spanning Two Biographies}

Despina Anaç, Marko Paşa (Pitsipios), 1824-1888, İstanbul, Türkiye Kızılay Derneği yay., Eylül 2019 (ciltli, $21 \times 29$ cm., 254 s., resim, tıpkıbasım) ISBN-978-605-5599-41-6

Sefa Saygılı ve Cihan Okuyucu, Arşiv Belgeleri Işı̆̆̆ında Marko Paşa: Hayatı - Çevresi - Şahsiyeti, İstanbul, Büyüyenay Yayınları, Ekim 2020 (13x21 cm., 277 s., resim, tıpkıbasım, dizin) ISBN 978-605-7683-51-9

Şeref Etker ${ }^{1}$ (])

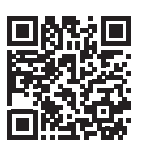

'Dr., İstanbul, Türkiye

ORCID: S.. E. 0000-0001-6966-8816

Sorumlu yazar/Corresponding author:

Şeref Etker,

Istanbul, Türkiye

E-posta/E-mail: serefetker@gmail.com

Başvuru/Submitted: 13.03.2021 • Kabul/Accepted: 14.05.2021 • Online yayın / Published online: 05.07.2021

Atıf/Citation: Etker, Şeref. "Marko Paşa: Iki Biyografiye Sığmayan Bir Efsane." Osmanlı Bilimi Araştırmaları 22, 2 (2021): 359-369. 
Bir yıl arayla yayımlanan iki biyografisinin kapağında Marko Paşa’nın aynı fotoğrafı kullanılmıştır: ${ }^{1} \mathrm{Bu}$ resminde Marko Paşa, Azizi fesi, dalgın bakışlı matruş portresiyle, sanki kendisi hakkında yazılıp söylenenleri izlemektedir...

Birinci biyografi (D. Anaç) aile öyküsü çerçevesinde oluşturulmuştur; torunlarının özel arşivine Paşa'nın ilkokul kayıtları, T.C. Cumhurbaşkanlığı Devlet Arşivleri Başkanlığı Osmanlı Arşivi (BOA) ile Kızılhaç’ın Cenevre'deki genel merkezinde bulunan belgeler eklenmiştir. Arşiv belgelerine daha geniş yer verilen ikinci biyografide (S. Saygılı \& C. Okuyucu), birinci biyografideki bilgiler gözden geçirilerek tartışılmış ve bazı düzeltmeler yapılmıştır.

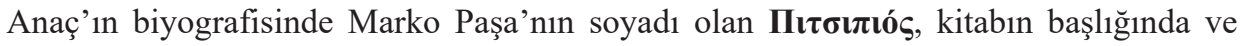
metin içinde, Latin harflerine "Pitsipios" olarak çevrilmiştir. Yunancada $\tau \varsigma$ harfleri birleşik olarak ç sessizine karşılık kullanılmaktadır. Yazarın kendi soyadı Avó $\tau \varsigma$ da "Anaç” biçiminde

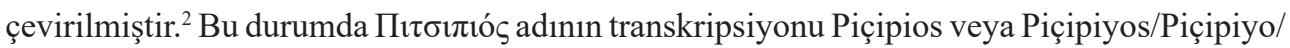
Piçipiyu olmalıdır. ${ }^{3}$ Dr. Marko Bey Piçipiyos'un adı, Dersaadet Cemiyet-i Tıbbiye-i Şahane toplantılarında ${ }^{4}$ ve Gazette médicale d'Orient'da yayımlanan makalelerinde Marc Picipio (Piçipio) olarak geçmektedir. ${ }^{5} \mathrm{Bu}$ adın Batı dillerinde "Pitzipio/Pizipio" olarak yazıldı̆̆ görülmektedir. Marko Paşa'nın oğlu Yorgi Bey ise kartvizitine soyadını "Pişipiyos” olarak yazdırmıştır. ${ }^{6}$

Dr. Marko Paşa'nın soyadının Apostolidis ('A $\pi \circ \sigma \tau o \lambda i ́ \delta \eta \varsigma)$ olarak yazılmasının yanlış olduğu belirtilmektedir. Paşa'nın Kuzguncuk’taki mezarına işlendikten sonra yakın zamanda değiştirilmiş olan bu soyadının babasının adından (Apostolis) geldiği varsayılabilirse de ayrıca üzerinde durulmamıştır.?

1 Vasilaki Kargopulo / Basile Kargopoulo fotoğrafhanesi (İstanbul, c. 1860). Kaynak gösterilmemiştir.

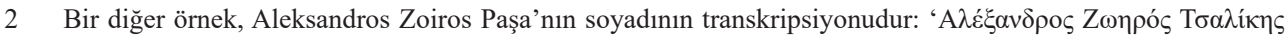
(Çalikis/Çaliki).

3 Ailenin soyadı Üsküdar Kaymakamlığı Nüfus Müdürlügü kayıtlarına "Piçipu” olarak geçmiştir: Despina Anaç, Marko Paşa (Pitsipios), 1824-1888, 104.

4 Marc (Marko) Picipio, Cemiyet-i Tibbiye-i Şahane'nin ilk üyeleri arasındadır, Gazette médicale d'Orient (publiée par la Société Impériale de Médecine de Constantinople) II, 1 (avril 1858): 19, (Membres titulaires [résidants]). Dernek yönetimine 15 Ağustos 1858 tarihinde “özel sekreter" olarak girmiş; 15 Ağustos 1861'de başkan seçilmiş, ancak başkanlığı kabul edemeyeceğini bildirmiştir: Gazette médicale d'Orient V, 7 (octobre 1861): 107 (Séance du 23 août).

5 M. le Docteur Marc Picipio, "Observation d'hématocèle péri-utèrine suivie de guérison" (lue à la Société [impériale de Médecine de Constantinople] du 5 décembre 1856), Gazette médicale d'Orient, I, 2 (mai 1857): 23-25; Marc Picipio, "Observation d'entéro-épiplocèle droite étranglée depuis quatre jours; opération; accidents consécutifs; mort; remarques," Gazette médicale d'Orient II, 3 (juin 1858): 48-50; Marc Picipio (professeur à l'École Impériale de Médecine), "Dragonneaux au nombre de sept, développés dans les membres inférieurs; apparition brusque des accidents après huit mois d'incubation; phénomènes consécutifs; guérison; remarques," Gazette médicale d'Orient II, 5 (août 1858): 85-89; M.[Marc] A.[Apostolis] Picipio "De quelques médicaments populaires," Gazette médicale d'Orient V, 2 (mai 1861): 17-21.

6 Anaç, 96, Georges M. Picipios / Jorj M. Pişipiyos.

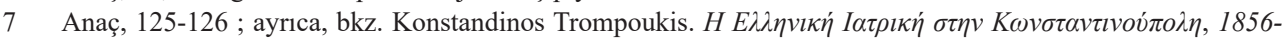



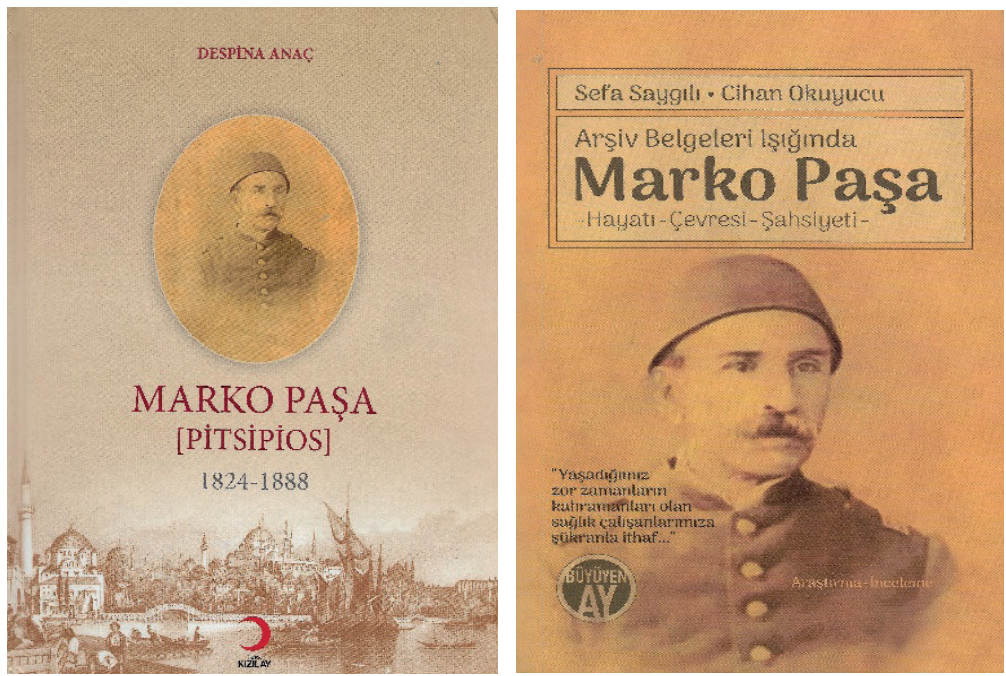

Marko Piçipiyo'nun doğum veya vaftiz kayıtlarının orijinalleri bulunamamıştır; ${ }^{8}$ yayınlarda 1824 yılında doğduğu tekrarlanagelmektedir. Buna karşılık, bulunan kayıtlar, doğum yeri olan Siros / Şire adasında 1837 ile 1842 yılları arasında okula devam ettiğini göstermektedir. ${ }^{9}$ Okulunun beş yillık bir ilkokul olduğunu kabul edersek, 1824 doğumlu Marko okula 13 yaşında başlamış olur ki, bu taşrada yaşayan çocuklar için bile oldukça geç bir okul yaşıdır.

Bir başka resmi kayıt Marko Paşa'y1 1244, İstanbul doğumlu olarak göstermektedir. ${ }^{10}$ Her ne kadar, Marko Paşa'nın İstanbul değil, Siros doğumlu olduğu bilinmekte ise de M. 1828/1829 yılında doğmuş olması yayımlanan okul belgesi ile daha tutarlıdır. Marko Piçipiyo'nun adada ilk öğrenimi tamamladıktan sonra, İstanbul'a gelerek Tıbbiye'nin ihzari veya ibtidai sınıfına girdiği düşünülebilir. Bu yıllarda Mekteb-i Tıbbiye-i Şahane'de öğretim: 3 yıl hazırlık ve 4 yıl tıp olmak üzere toplam 7 yıldır. Marko Piçipiyo'nun, 1844'te 15-16

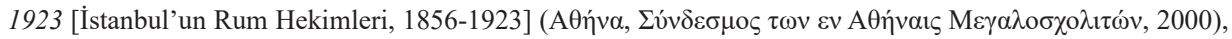

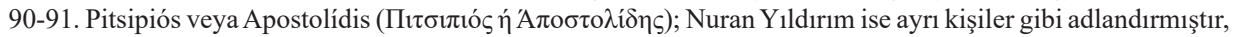
bkz. Tiphane-i Amire ve Mekteb-i Tibbiye-i Şahane'den İstanbul Tip Fakültesi'ne (İstanbul : BETIMM yay., 2019), 279, Marko Paşa (Marko Apostolidis); 291, Picipio, Marc Apostoly.

8 Marko Paşa Katolik Rum milletindendir, bkz. Христо Т. Стамболски [Dr. Hristo Tanyev Stambolski, 18431932], Автобиография, дневнитси и спомени (Avtobiografiya, Dnevnitsi i Spomeni [Otobiyografi, Günlükler ve Anılar]), c. II (София, Дьржавна печатница, 1927), 284, “Марко паша е християнинъ гръко-католикъ ; баща му е биль Далматинецъ, капитанъ Пичипио...” (Marko Paşa, bir Rum-Katolik Hıristiyandır; babas1 Dalmaçyalı kaptan Piçipio...).

9 Anaç, 19, 29-33.

10 Anaç, 105. Üsküdar Belediyesi Arşivi (?): Mekteb-i Tıbbiye Nazırı 'Saadetlü' Marko Paşa Hazretleri, 1244 Dersaadet (İstanbul). Bu yıllarda Hicri takvimin kullanıldığını varsayarsak, Marko Paşa, Temmuz 1828 - Haziran 1829 arasında doğmuş olmalıdır. (Rumi takvime göre 1244 yılı Mart 1829 - Şubat 1830.) Aynı belgelerde Marko Paşa'nın oğlu Yorgi için verilen doğum tarihi: 01.07.1875 ve [R.] 1291 / 1875 tarihi Anaç tarafindan doğru kabul edilmektedir (s.93). 
yaşlarında Askeri Tıbbiye'ye girerek H. 1267/1851 yılında 23 yaşında mezun olması akla daha yakındır. Marko Paşa'nın 64 yaşında öldüğünün bildirilmesi nedeniyle doğum tarihi 1824 olarak verilmektedir. Ancak bu tarih doğrulanmamıştır. ${ }^{11}$

Nitekim, Nasırüddin Şah'ın seyahatnamesinde, 25 Ağustos 1873 günü İstanbul'da doktoru Tholozan tarafından kendisine takdim edilen Marko Paşa'yı iyi Fransızca konuşan “kırk beş yaşında, zayıf, soluk benizli; sakalını kesmiş (matruş), bıyıklı” bir kişi olarak tanıtmaktadır. ${ }^{12}$ İran Şahı, Marko Paşa’nın yaşını kendisinden sorup öğrendiyse, doğum tarihinin 1828 olduğunu söyleyebilecek bir tanığımız da var demektir - Paşa'nın kendisini Şah'a olduğundan genç göstermek istemesi için bir neden de yoktur !

Marko Paşa'nın babası Apostolis Pitsipios/Piçipiyos için, basılı bir kaynakta verilen (9. Sütun): ${ }^{13} 1837$ tarihi onun ölüm tarihi değil, (Yunanistan Krallığına) "Liyakat yemini” ettiği tarihtir. Daha ilginci, Apostolis Piçipiyos'un memleketinin İstanbul (Konstantinupol[is]) olarak belirtilmiş olmasıdır (4. sütun). ${ }^{14}$ Aynı zamanda İngiliz uyruğunda olan Apostolis Picipio, İngiliz Foreign Office kayıtlarından anlaşıldığına göre, 1858 yılında ölmüştür. ${ }^{15}$ Kitapta hiç adı geçmeyen bir kişi ise Marko Paşa'nın annesidir ve onun özellikle araştırılmamış olması çalışmanın önemli bir eksiğidir.

Sorgulanması gereken bir diğer konu da Siros adalı bir ailenin çocuğunun Askeri Tıbbiye'ye girişine kimin veya kimlerin aracılık ettiği ve/veya kefil olduğudur ? Burada ailenin İstanbul'daki uzak - yakın akrabalarının düşünülmesi gerekir. Dr. Konstantin Karatodori ailenin Fenerli hısımlarından biridir.

11 "Nécrologie," Revue médico-pharmaceutique (İstanbul) I, 11 (30 novembre 1888): 176, “S.E. le Dr. Marco Pacha, Directeur de l'École I. de Médecine, vient de succomber aux suites d'une longue et douloureuse maladie à l'âge de 64 ans. Le défunt fut médecin particulier de feu le Sultan Abd-ul-Aziz d'heureuse mémoire. S.M.I. le Sultan Abdul Hamid II, l'a nommé sénateur. Il a occupé le poste de directeur de l'École I. de Médecine pendant 16 ans. Ses funérailles ont eu lieu le 4 [novembre] courant au mileu d'une nombreuse assistance, parmi laquelle on remarquait S. Exc. le Dr. Mavrogény Pacha, Médecin en chef de S.M.I. le Sultan; S.Exc. Ferdinand Pacha, Président du Conseil médical civil; S.Exc. le Dr. Saib Pacha, Directeur de 1'École I. de Médecine..."

12 The Diary of H.M. The Shah of Persia [Nasir al-Din] during His Tour through Europe in A.D. 1873, trans. by James W. Redhouse (London, John Murray, 1874), 397-398, (1 Receb 1290 / 25 Ağustos 1873) "To-day [Dr. Joseph-Désiré] Tholozan brought Marco Pasha to an audience, who is the Sultan's Chief Physician; and with him I had a good deal of conversation. He is a man of forty-five years of age, thin, sallow, who shaves his beard and wears mustachios. He speaks French well; they say that, by origin, he is Greek." (Islahat fermanıyla gayrimüslimlere sakal bırakma izni verildiği halde, Marko Paşa sakal uzatmamıştır. Dolayısıyla Orhan Pamuk'un "Padişah Abdülaziz'in başhekimi karasakallı Rum doktor Marko Paşa" imgesi de yanıltıcıdır: Veba Geceleri, 1. bs. (İstanbul: Yap1 Kredi Yayınları, 2021), 18.

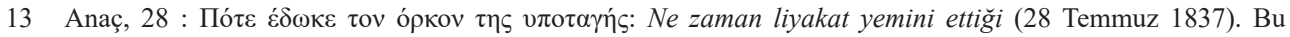
kaynağın künyesi yazılmamıştır.

14 Pitsipios/Pitzipio'lara ilişkin bir başka söylence : ailenin İstanbul'dan Cenova'ya, oradan Dalmaçya ve Sakız adasına göç ettikleridir. Apostol Piçipiyo'yu aslen Zanta (Zakintos) adasından sayan belgenin bu öyküyü desteklediği düşünülebilir, bkz. Saygılı \& Okuyucu, 160.

15 Public Record Office, London FO 141/36 Pt 1, John Petherick to John Green, Khartoum, July 241858. 
Türk Kızılayı tarafından yayımlanan kitabın girişinde ve metin içinde yazım özensizlikleri dikkati çekmektedir: "Meclis-i Umuru Sıhhiye" ve "Mecruhin ve Marda-y1 Askeriyeye İmdat ve Muavenet Cemiyeti” (s. 61, "Mecruhin ve Marza-i Askeriyeye İmdad ve Muavenet Cemiyeti”), gibi. ${ }^{16}$ "[Marko Pitsipios] mezuniyet sonrası okulun Cerrahi Kliniğine şef olarak atandı... Paşa rütbesine yükseltilen ilk tabip oldu" cümlesinin açılması gerekir: Marko Bey muallim muavini ve chef de clinique olarak atanmıştır; "Paşa" ise bir rütbe değil, unvandır (s. 36). Yine "Marko Paşa, tıpla ilgili yazdığı Risale-i Hikemiyye-i Aziziyye fi Beyan-l Terkib-i Ecza-yı Tıbbiye adlı risaleleri üç cilt halinde masraflarını karşılayarak yayınlamış" denilmekle birlikte (s. 139), Marko Paşa'nın bu adı taşıyan yayımlanmış bir kitabı yoktur.

D. Anaç, Marko Paşa (Pitsipios)'da yayımladı̆̆ı BOA belgeleri arasında adı geçen bir 'Dr. Marko'nun Dr. Marko Piçipiyo olmadığı, bu belgelerin kitaba yanlışlıkla alındığı anlaşılmaktadır. ${ }^{17}$ (28 Ramazan 1262/ 19 Eylül 1846 tarihli taltif belgesi oluşturulurken Marko Piçipiyo henüz Tıbbiye öğrencisidir.) Kitapta yer verilen 1890 tarihli, Marko imzalı belgenin de ('Marko Paşa'ya verilen Nişan-1 Osmani ödülü') Marko Paşa'ya ait olmadığı yazılış tarihinden bellidir (s. 118). Sultan Abdülaziz’in 4 Haziran 1876 günü gerçekleşen otopsisine ait, orijinali Fransızca olan '19 Doktorla Marko Paşa’nın İmzaladığı Rapor' olarak sunulan belge Marko Paşa’nın 1881 tarihindeki mahkeme ifadesidir (s. 202-203). ${ }^{18}$

Sultan Abdülaziz'in doktoru Marko Paşa için, 1865'te Çırağan Sarayının karşısında Kuzguncuk'ta bir ev yaptırması anlaşılabilir bir seçimdir. Buna karşın Anadolu Kavağı'ndaki köşkün yapılış nedeni ve konumu ise yoruma açıktır. Bu köşk bir salgın hastalık sırasında Padişahın sığınma evi olarak düşünülmüş olabilir mi ? Gerçekten Marko Paşa'ya ait bir köşk ise, yapımına, satışına vb. ilişkin izin belgeleri bulunmalıdır. Marko Paşa Demirkapı Tıbbiyesinde muallim iken nerede oturduğu bilinmiyor : İstanbul'da 1878'deki salgın sırasında hastaneye dönüştürülen konak Dr. Marko Paşa'nın mıdır ? ${ }^{19}$ Bazı belgelerin ise Osmanlı Arşivinde olmadığı anlaşılmaktadır. Örneğin, yabancı kaynaklardan Marko Paşa’ya verildiğini öğrendiğimiz: Prusya Königlicher Kronen-orden 2. Klasse mit dem Stern, Oesterreicher-Kaiserlicher Leopold-Orden, Kommandeurkreuz ve Commandeur de la Légion d'Honneur nişanlarının takılabilmesi için yine izin belgeleri olmalıdır.

16 Kerem Kınık, 'Takdim', Anaç, 10-11.

17 Anaç, 140-141, BOA C.SH. 12 562-1, 28 Ramazan 1262; s. 148/149, BOA İ.DH. 350/230 94-1, 20 Şevval 1272; s. 150/151, BOA İ.DH. 350/23094-1, 10 Zilkade 1272; s. 152/153, BOA A.DVN.MHM. 18 9-1, evahir-i Zilkade 1272; s. 154/155, BOA A.MKT.NZD. 189 77-1, 4 Zilhicce 1272; BOA A.DVN.115 67 2-1, 29 Zilhicce 1272.

18 Abdülaziz'in otopsisinde 20 doktor bulunmuş; Mabeyn-i Hümayun Tabibi (Macar) Ömer Paşa raporu imzalamamıştır.

19 "Auf der Seraispitze in Stambul, inder Nähe der verfallenen Kiosks und Galerien, im Schatte der alten Cypressen, welche ehemaligen Garten des kaiserlischen Harems bezeichnen, sind fünf Baraken errichtet worden, in welche man die Typhus- und Blatterkranken gebracht hat. Höher hinauf in einem Marco Pacha gehörigen hause, ist das Typhus-Lazareth zu 200 Betten für kranke Frauen eingerichtet."Bodenbacher Anzeiger, 5. Jhrg., Nr. 14, 6. April 1878, 2 (Die Epidemie in Constantinopel). 
D. Anaç, kitabında Marko Paşa'ya değinen Türkçe kaynakların bir kısmını özetleyerek aldığı halde, dönemin - Sakız ve Siroz adalarında görülen birkaç kaynak dışında - Yunanca süreli ve süresiz yayınlardan yeterince yararlanmamıştır. ${ }^{20} \mathrm{Bu}$ kaynaklardaki bilginin bir sağlaması da yapılmamıştır. ${ }^{21}$ Kızılhaç belgelerinin gösterdiği gibi, diğer dillerdeki kaynaklar aynı derecede önemlidir ve öyle görülüyor ki, başka çalışmalar içinde değerlendirilecektir. ${ }^{22}$

\section{Tabib-i Has Cerrah Marko Bey Piçipiyo}

Saygılı \& Okuyucu'nun Marko Paşa biyografisinde 150'ye yakın arşiv belgesi incelenerek tarihsel bağlamlarında değerlendirilmeye çalışılmıştır. ${ }^{23}$ Kitapta, BOA belgelerinin yanında, orijinalleri BnF'da (Paris) bulunan bazı yazışmaların çevirileri verilmiştir. ${ }^{24}$

Bu biyografide Marko Paşa’nın soyadının yazımıyla ilgili bir açıklama yapılarak, Osmanlı belgelerinde ismin "Piçipu, Piçisuyu, Piçipuyu, vs. gibi farklı şekillerde imla edilmekte"

20 Despina Papadopulu-Anaç, kitabını Yunanca olarak da yayımladı̆̆ı halde kaynakçası aynıdır, bkz. $\Delta \varepsilon \dot{\sigma} \sigma o ı v \alpha \varsigma$

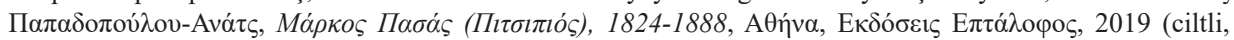
$21 \times 29$ cm., 256 s., resim, tıpkıbasim) ISBN 978-618-00-1114-2.

21 Örneğin, Marko Paşa'nın 1867 yılında evlendiğini gösteren belgede onun 1823 İstanbul doğumlu olduğu yazılıdır! Anaç, 87.

22 Medical Times and Gazette (London), vol. I (1862), January 11, 1862, 42-44 "The late Sultan and the medical service of the Serail" (Constantinople, November 30 [1862]) :

"With the death of Abdul Medjid, [Constantin] Caratheodory's star went down; and the Sultan Abdul Aziz, made Dr. Marco Pitzipio his personal Physician in Ordinary. This gentleman, a Greek, has been educated at the Medical School of Constantinople; He is a pupil of [Lorenz] Rigler's, late Professor of the Medical Clinique, and of Caratheodory's, the Professor of Clinical Surgery, and is, no doubt, of the ablest young Doctors who have been educated here. He has chiefly devoted himself to Surgery, and was for several years Clinical Assistant to Caratheodory, whom he also replaced at his chair for some time. He is a great favorite of Djemaleddin [Cemaleddin] Effendi, the quondam Director of the Medical School, and has a large practice amongst the Turks. He has for several years enjoyed the confidence of our Ambassador, Sir Henry Bulwer, whom he attended in his late illness, together with Mr. Dixon [Edward Dalziel Dickson], Drs. [Julius van] Millingen and Caratheodory. Before the accession of the present Sultan [Abdülaziz], Marco Bey (Pitzipio had then the rank of Colonel, and therefore the title of Bey) was one of the few who were admitted to the presence of the heir presumptive, who as is the wont with the Oriental princes, was obliged to live in great seclusion. He served him without having an appointment as Physician to the Serail, not only as Doctor, but also as confidant; and it was therefore only natural that, on the accession of Abdul Aziz, Marco Pitzipio should have become Imperial favourite, and should have obtained the highest place in the Medical World of this [Ottoman] Empire. Marco Bey became Marco Pasha, with the rank of Brigadier, Physician Ordinary to the Sultan, Chief Physician to the Serail, and General Inspector of all the Military Hospitals of the capital... Whether Marco possesses the necessary qualifications for effecting a thorough reform in the Medical service, it is not for me to determine; but I believe I may safely predict that his natural shrewdness will soon put a limit to the great activity and youthful zeal which he displayed at first; as he who exceeds certain limits, proves in the East always useless for the public good, and only entails absolute ruin upon himself."

23 Saygılı \& Okuyucu, hazırladıkları Marko Paşa biyografisine bir savunma ile başlamak gereğini duymuşlardır: "Bu çalışmayı eline alan ve yazarları tanıyan bir okuyucu ilk elde şaşırabilir ve 'Allah Allah, böyle bir konuyu yazmak bunlara mı kaldı !' diye düşünebilir. Bu bakış; tarihi derinlikten, kültür ve medeniyetimizi hakiki manasıyla kavrayamamaktan gelen, modern ulusalcı telakkilerle malul, sı̆̆ bir bakıştır.” (s. 9).

24 Saygılı \& Okuyucu'nun kitabına Anaç'ın kitabında yer alan belgeler içinde Marko Paşa ile ilgili olmayan yukarıda dn.15'de künyeleri verilen - belgeler alınmamıştır (s. 42). 
olduğu belirtilmiştir. ${ }^{25}$ Arap harfleriyle yazılan isimlerin yanlış okunabileceğine dikkat çekmek gerekir. Örneğin, HR.TH. 251.38 belgesinde "Yorgi veled-i Apostol Piçipiyo" adının "Piçisiyo" ; BEO 2450183692 (Maliye 182261) belgesinde "Piçiyu" olarak da yazıldı̆̆ görülmektedir. ${ }^{26}$

Marko Piçipiyo'nun annesi İstanbul'da “Madame Picipio" (Pizipio) olarak tanınmaktadar. ${ }^{27}$ Mesleğinin ebelik olduğu anlaşılan Madam Piçipiyo'nun 1843 yılında Mekteb-i Tıbbiye-i Şahane'de çalışmaya başladığı bilgisi gözden kaçmıştır. ${ }^{28}$ Bu durumda Apostol Piçipiyo, eşi ve çocuklarıyla birlikte bu tarihten önce İstanbul'a yerleşmiş olmalıdır.

Marko Paşa’nın 25 yıllık hekimlik kariyeri üç döneme ayrılabilir. Saygılı \& Okuyucu bu bölümleyi padişahlara göre yapmışlardır :

1851 yılında Mekteb-i Tibbiye-i Şahane'den (Askeri Tıbbiye) mezuniyetinden, 1860'da Cerrahi Kliniğine muallim oluşuna kadar ilk 10 yıl;

1861 'de Askeri Hastaneler Nazırı oluşundan, 1876'da Abdülaziz'in ölümüne kadar geçen 15 yıl, ve1877'den, hastalanarak Tıbbiye Nazırlığından ayrıldığı 1887 yılına kadar geçen 10 yıldır.

Marko Paşa'nın kariyerinin ilk dönemi belirsizliklerle doludurdur ve çalışmalarında bu tarihlere ait bütün BOA belgelerini gözden geçiren Saygılı \& Okuyucu saptadıkları tutarsızlıklara işaret etmişlerdir. Mezuniyetinden hemen sonra, 1851 'de cerrahi muallim muavini olan Dr. Marko Bey Piçipiyo, 1852 'de materia medica öğretmeni olarak görülmektedir. ${ }^{29}$ Yine, 1857 'de Nebatat Muallimi iken, ${ }^{30}$ daldan dala atlayarak, 1860 içinde önce kinin sulfat (solfato) incelemesi yapan

25 Saygilı \& Okuyucu, 158 ve dn. 1.

26 Saygılı \& Okuyucu, 159-162, 'Yorgi'nin Mirası Meselesi' başlıklı bölümde yer verilen bir belgede (BOA, BEO 2450.183692.1. . "Mekteb-i Tibbiye esbak Nazırı Marko Paşa'nın... küçük biraderi Yorgi veled-i Apostol Piçipiyo"dan söz edilmesine karşın, bir öncki bölümün başlığı "Marko Paşa’nın Ağabeyi Yorgi (Yorgaki)"dir (s. 154).

27 "The Levant Herald [İstanbul] gives these particulars of the recent ceremony attendant upon the birth of a Princess [Saliha Sultan, d. 10 Ağustos 1862] in Turkey: 'When the ladies of distinguished personages present themselves on the occasion of the Sultan's confinement, the custom is for them to offer their congratulations to the Sultan... on the recent occasion they were introduced according to the rank and position of their husbands; first the lady of the Grand Vizier, then the lady of the Minister of Foreign Affairs, afterwards the wife of the Sheikh-ul-Islam, followed by the remainder; there were also christian ladies present, amongst others Mme. Guatelli, Mme. Picipio (the mother of Marco Pasha), \&c" Sun (London), September 1, 1862, 1.

28 "Rapport sur les travaux de l'École de Médecine de Galata-Sérail, pendant l'année scolaire 1258-1259 (18421843)," Journal de Constantinople et des Intérêts Orientaux, 52, 26 septembre 1843, aktaran Yeșim Iș11 Ülman, "Portraits of Italians in Health Affairs in 19th century Istanbul: Dr. Castaldi, Pharmacist A. Calleja, Midwife Messani," Quaderni di Oriente Moderno, 88, 1 (2008): 135-139. Bu makalede Mme. Madam Pizipio (Picipio) yanlışlıkla İtalyan olarak gösterilmiştir.

29 Wiener Medizinische Wochenschrift, 2. Jhrg., Nr. 38, 18. September, 1852, 616. Bu tarihte Tibbiye'de öğretim: 4 yıl hazırlık ve 6 yil tıp eğitimi olarak değiştirilmiştir. Botanik ve zooloji dersleri Dr. Konstantin Karatodori; materia medica (müfredat-1 tıb ve fenn-i tedavi) dersleri Dr. Sarandis Arhiyenis tarafindan verilmektedir.

30 Sayglı \& Okuyucu, 43, BOA. A.MKT.UM. 277 65, 13 Şaban 1273 (8 Nisan 1857). 
"Professeur de matière médicale", ${ }^{31}$ bir kaç ay sonra cerrahi profesörü olmuştur. ${ }^{32}$ Bunu çağın bir özelliği sayabiliriz. Marko Paşa'nın adı dönemin İstanbul'daki iyi cerrahları arasında geçer. ${ }^{33}$

Saygılı \& Okuyucu'ya göre, Marko Paşa'nın “ser-etibba-yı Hazret-i Şehriyari unvanının zikredildiği en eski arşiv belgesinin” 25 Muharrem 1279 (22 Temmuz 1862) tarihli oluşu nedeniyle sertabipliğe ne zaman getirildiğinin belirsizdir. Bazı BOA belgelerinin sağlaması Cemiyet-i Tıbbiye-i Şahane'nin yayınlarıyla yapılabilir; örneğin, Dr. Marko Piçipiyo'nun adı, bu tarihten bir y1l önce, Gazette médicale d'Orient'1n Temmuz 1861 sayısında Sultan Abdülaziz'in sertabibi (médecin en chef) olarak geçmektedir. ${ }^{34}$ Sultan Abdülaziz'in veliahtlığından beri özel hekimliğini yapan Marko Paşa’nın onun kişisel işlerine ve yabancılarla diplomatik denilebilecek ilişkilerine aracılık ettiği bilinmektedir.

Marko Paşa'nın özgeçmişiyle ilgili arşiv belgelerinde eğitim için Avrupa'ya gittiğine ilişkin her hangi bir not bulunmamaktadır. Yalnız, Cemal Kutay'ın Avrupa'da Sultan Aziz adlı kitabında Marko Paşa için “ihtisasını Paris’te yapmıştır” denilmiştir. ${ }^{35}$ Bunu destekleyen bir bilgiyi The Lancet dergisinde yayımlanan Marko Paşa'nın 1867 yazında İngiltere'de Kraliyet Victoria Asker Hastanesini (Netley, Southampton) ziyaretinin anlatıldığ 1 bir haberde buluyoruz: burada, kendisinin "Fransa'da eğitim gördüğü ve en saf Paris Fransızcasıyla konuştuğu" kaydedilmiştir. ${ }^{36}$

Sultan Abdülaziz'in ölümü ile ilgili raporlar "Marko Paşa ve İkinci Abdülhamid" bölümüne alınmıştır. Bu bölümde Dr. Marko Paşa hakkındaki şikayetlere de yer verilmiştir. “Arşiv belgelerine bakılırsa Marko Paşa'nın hayatındaki en büyük problemlerden biri Dr. Niko ile yaşadığı sıkıntılardır”. Ancak erişilebilen arşiv belgelerinin konuları bakımından dağılımı, araştırmalarda belirli olaylara odaklanılmasına, dolayısıyla da yaşamöykülerinin ağırlık merkezlerinde sapmalara neden olmaktadır. Seretibba olduğu yıllarda Marko Paşa'nın başlıca uğraşısı bu şikayetlerde sözü edilen konular olmasa gerektir. Marko Paşa’nın adını efsaneleştiren öyküler son döneme (II. Abdülhamid) aittir ve Saygılı \& Okuyucu tarafindan

31 "Rapport lu au Conseil Impérial de Médecine, le 3 Mars (19 Février) 1860, sur vingt-six échantillons de Sulfate de Quinine", Gaz. méd. d'Orient IV, 1 (avril 1860): 18-19. Marko Paşa bu raporu, "M.A. Picipio, professeur de matière médicale" olarak imzalamıştır.

32 "M. Constantin Carathéodori, profésseur de Clinique chirurgicale et M. Etienne [Stephanos] Carathéodori, profésseur de botanique à l'École Impériale de Médecine, ont été autorisés à se faire remplacer dans leurs chairs respectives par M. Marco-bey Pitzipio et par M. [Pavlaki] Fénerli", Gazette médicale d'Orient IV, 5 (août 1860): 92.

33 “There are no 'pure Surgeons' here. C.[Constantin] Carathéodory, [Richard] Sarrell, Marcos Pitzipio, and [Jacques] De Castro, are considered the best operators," Medical Times and Gazette (Londra), vol. II (1861), August 10, 1861, 144-146 (European Medicine in Turkey).

34 "Le Dr. Marco Picipio, médecin en chef de S.M. le Sultan Abd-ul-Aziz, promu au grade de liva il y a quelques jours, vient d'être nommé inspecteur-général des hôpitaux militaires de la capitale," Gazette médicale d'Orient $\mathrm{V}, 4$ (juillet 1861): 64.

35 Cemal Kutay, Avrupa'da Sultan Aziz, 2. bs. (İstanbul: Posta Kutusu yay., 1977), 158. Cemal Kutay’ın kitabının eleştirisi için, bkz. Saygılı \& Okuyucu, 76-82.

36 The Lancet, vol. II (1867), July 27, 1867, 109. "Marco Pasha, Physician-in-Chief to the Sultan [Abdülaziz], and Director-General of the Medical Department of the Turkish Army, paid an official visit to the Royal Victoria Hospital, Netley [Southampton] on Tuesday [July 22, 1867]... This eminent person is, we understand, a Greek, educated in France. He speaks the language with the purest Parisian accent, and is evidently thoroughly acquainted with all the details of military medical education" (vurgulandi). 
genişçe derlenmiştir. 'Senatör' Marko Paşa'nın bu dönemde artık Saray'da sözünü dinletebileceği pek kimse kalmamıştır.

Kitaptaki yazım yanlışlara örnek olarak, ünlü Dr. Zambako Paşa'nın adının "Doktor Jambako" (s. 191) ve İhtiyol üreticisi Hamburg Ichthyol-Gesellschaft firmasının "Hamburg'daki İştiyol Cemiyeti” (s. 90) okunması gösterilebilir. Dr. Niko’nun dilekçesinde geçen "kondoz (?)" adlı zehir ise kunduz (zürrah, cantharide)'dir (s. 123). Marko Paşa'nın kızkardeşi Evridik Hanım'ın "sekene Hamesi (?) Prensesi” olarak okunan unvanı "Sakız Adası Prensesi” olacaktır (s. 171). Doktor Mösyö Kastori (s. 98) ile Dr. Kastro (s. 103) aynı kişidir (Dr. Jak/Jacques de Castro). Marko Paşa'nın ölüm tarihi 2 Kasım yerine 14 Kasım 1888 olarak verilmiş (s. 109, s. 227); başka yerde bu tarih alıntılanan makalenin hatası olarak gösterilmiştir (s. 144 dn. 1). ${ }^{37}$ Bu yanlışların bir kısmı BOA belgeleri için hazırlanan özetlerin olduğu gibi aktarılmasından kaynaklanmıştır. ${ }^{38}$ Zoiros Paşa'nın, Marko Paşa'nın mezarı başında yaptığı konuşmanın Türkçe özetinin son paragrafı yayımlanmamıştır. ${ }^{39}$

\section{Marko Paşa Reformist mi, 'Affairiste’ mi ?}

Marko Paşa, döneminin yayınlarında: yetkin bir organizatör ve "vulgarisateur intelligent" olarak nitelenir. $\mathrm{Bu}$ deyim, ona popülerliği yanında bir pratisyen olarak başarılı olmasını sağlayan iletişim becerisini tanımlar. ${ }^{40}$ Marko Paşa organizasyon becerisini askeri hastanelerin yönetimine getirildikten sonra göstermiştir. Kırım Savaşı (1853-1856) sırasında Osmanlı ordusunda askeri sağlık hizmetleri etkisiz kalmıştır: tabipler, cerrahlar ve yardımcı sağlık personelinin deneyimsiz, mesleki bilgi ve beceri bakımından yetersiz olduğu görülmüş; zayiat yüksek olmuştur. ${ }^{41} \mathrm{Bu}$ durumda Marko Paşa'nın üstlendiği misyon ancak bir yeniden yapılanma olabilirdi. ${ }^{42}$

37 Marko Paşa’nın ölüm tarihi 3 Kasım 1888 olarak veren bir kaynak : Neue Freie Presse (Viyana), Nr. 8697, 9. November $1888,5$.

38 Anaç'ın kitabındaki bir belgede yer alan (s. 105) ve Saygılı \& Okuyucu tarafindan "Bedros kızı Aleksandros" olarak okunan isim "İliyas oğlu Aleksandros" olmalıdır (s. 183). Bedros Ermeni, Aleksandros Yunan dillerinde erkek adıdır.

39 Konuşmanın son paragrafı şöyledir: "1862 senesinde sertababet-i Şehriyari uhdesinde kalmak üzre Mekteb-i Tıbbiye-i Şahane ve Umur-1 Tıbbiye-i Mülkiye Nezaretine tayin kılınmış idi. Bundan bir sene akdem duçar olduğu illetden dolayı esir-i firaş olub pek çok alam ve ızdırab çekmiş ise de kemal-i sabır ve metanetle tahammül etmişdir. İște bugün kendisini tanıyan bilcümle zevatı esef-i azim içinde terk ile cihan-1 fenaya icray1 veda-1 ebedi ederek şu gördüğünüz yerde yatıyor. Marko Paşa! Mekteb-i Tıbbiye-i Şahane Nazır Vekili ve umum muallimleri ve muavinleri ve memurin ve şakirdanı tarafindan sana son ihtiramatı eda ederim. Adieu Marko Paşa, Adieu," Tarik, numero 1658, 2 Rebiyü’l-ahir 1306 / 25 Teşrin-i evvel 1304 / 6 Teşrin-i sani [Kasım] 1888, s. 1, sü. 4-5.

40 Alfred de Caston, Constantinople en 1869 (Paris: G. Kugelmann, 1868), 270. Telkin denilince de ilk akla gelen Marko Paşa'dır : "Mesela, burada hastalar üzerinde telkin hassası en kuvvetli olan Marko Paşadır. Kendisine Neron gibi kainatın en muazzam, en cabbar hastasını getirin, o, telkin kudretinin sayesinde onu az bir zaman içinde melek gibi yapmaktadır...," Osman Cemal (Kaygıl1), "Ahrette Tababet !", Akbaba, sayı 134, 1 Ağustos 1936, 14.

41 "However, the greatest drawback to this [Medical] School, which is specially destined for education of Army Surgeons, is the want of a sufficient Surgical education... The wretched standard of Turkish Army Surgeons generally became strikingly apparent during the last war with Russia," Medical Times and Gazette, vol. II (1862), November 22, 1862, 553-555 (Turkey. The Medical School).

42 "At the time of the accession of the present Sultan [Abdülaziz], fresh hopes of a regeneration of the [Turkish 
Sultan Abdülaziz, tahta geçer geçmez Saray'daki 28 tabipten 14'ünü uzaklaştırmıştır. Marko Paşa ise askeri tabipler arasında bir seçim yaparak başarısız bulduklarını görevden ayırmıştır. ${ }^{43}$ Bundan başka, Marko Paşa'nın önerisiyle Mekteb-i Tıbbiye-i Şahane muallimlerinin ücretleri 2000 ile 4500 kuruş arasında azaltılmıştır. Okulun re-organizasyonu için Paris’ten Prof. Alfred Velpeau'nun çağırılması gündeme gelmiştir. ${ }^{44}$

Marko Paşa, askeri hastanelere yeni bir çalışma düzeni getirmek istemiştir. Günümüzün askeri ve sivil eğitim hastaneleri için bile geçerli olabilecek bir rutinde: Tabipler, her sabah hastalarının vizitini yaptıktan sonra, toplanarak bir konsültasyon yapacak; bu toplantıda sağlık hizmetinin gereksinimleri gözden geçirilecek; ayrıca ilginç ve problemli olgular tartışılacak, güncel tıbbi ve bilimsel paylaşımlar yapılacaktır. Marko Paşa bu klinik toplantılarından günü gününe bilgilendirilmesini ve tutanaklarının kendisine iletilmesini emretmiştir. ${ }^{45}$

İstanbul'da yaşayan ve Marko Paşa'nın sağlık hizmetlerindeki reform girişimleri izleyen bir İngiliz hekimin değerlendirmesine göre, bu düzenlemelerden beklenen sonuçlar alınamamıştır; çünkü, en yetenekli ve çalışkan tabipler bile mesleklerinde liyakatın üstün tutulacağına inandırılamamıştır ! Dr. Marko Paşa'nın kendisi de cerrahlıktan giderek uzaklaşmış ; 1876 yılı Şubat ayı başında Sultan Abdülaziz'de oluşan bir çıbanı (karbonkül, şirpençe) açıp temizlemek de - Doktor olmayan Doktor - Macar Ömer Paşa'ya düşmüştür. ${ }^{46}$

Saygılı \& Okuyucu Askeri Tıbbiye'nin tarihçesi için, geniş ölçüde Kemal Özbay’ın Türk Asker Hekimliği Tarihi'nden yararlanmışlardır. ${ }^{47}$ Abdülaziz dönemi Tıbbiyesinin özel olarak incelenmesi gerektiğini düşünüyoruz. Mekteb-i Tıbbiye-i Şahane ve Eczacılık Mektebi’nin Abdülaziz dönemine ait kurumlar olarak gösterilmesi doğru değildir (s. 42).

Army Medical] Department were conceived, principally because Marco Pasha, his Physician in Ordinary, was himself a pupil of the [Imperial Military] Medical School, and was believed to nourish ideas of reform..." Medical Times and Gazette, vol. I (1864), June 18, 1864, 681-682.

43 "Denn es war einige der ersten Regierungsthätigkeiten Abdul Aziz's, dass er das Serail von seinem grossen Schwarme von Müssiggängern reinigte, und dass er die Zahl der 28 Serailärzte auf 14 reduzirte... Ebenso hat Marco Pascha eine grosse Zahl unfähiger Aerzte aus dem Armee Departmenten entlassen.” Wiener MedizinalHalle, Nr. 8, 13 Februar 1862, 77-78 (Die Aerzte des Serails).

44 British Medical Journal, vol. II (1863), August 1, 1863, 121.

45 Medical Times and Gazette, vol. II (1863), June 18, 1864, 681-682 "The rules made by Marco Pasha, the Inspector-General of the Hospitals, prescribe that after the Surgeons have visited their patients in the morning they shall all meet in consultation, and discuss the requirements of the Hospital, relate interesting cases under treatment, and talk over scientific questions, etc.; and that minutes of these proceedings shall be daily sent in to the Inspector-General. But as there is a total lack of scientific ardour amongst the Medical staff, and great dissatisfaction prevails amongst its most talented members on account of systematic neglect of merit, nothing whatever comes out of these daily meetings" (vurguland1).

46 Neue Freie Presse, Nr. 4129, 23. Februar 1876, 12. Ferik Ömer Paşa, Macar olarak tanınmasına karşın Viyana doğumlu bir Polonyalıdır.( "Omer Pascha stammt aus einer armen polnisch-jüdischen Familie," Pester Medizinisch-Chirurgische Press, 12. Jhrg., Nr. 31, 30. Juli 1876, 536.) Ömer Paşa’nın Tıp Fakültesi mezunu olmayıp bir 'sıhhiyeci' olduğu da bilinmektedir, bkz. Allgemeine Medicinischen Central-Zeitung (Berlin), XLV. Jhrg., 58. Stück, 19. Juli 1876, 726-727: “Omer Pascha, den Sultan Abdul Aziz vom Feldscher-Gehilfen zum Leibarzt und zur Würde eines Ferik, eines Feldmarschall-Lieutenants emporgehoben hatte" (vurgulandi).

47 Kemal Özbay (Tbp.Gen.), Türk Asker Hekimliği ve Asker Hastaneleri, c. I-III (İstanbul: Yörük Basımevi, 1976-1981). 
Mekteb-i Tıbbiye-i Şahane içinde Dr. Marko Paşa'nın pozisyonunu etkileyen bir çevresi olduğu değerlendirilebilir. Okulun kuruluşundaki “Josephinum ekolü” yerini Dr. Antoine-Sulpice Fauvel'in yönetimindeki "Fransız ekolüne" bırakırken, ${ }^{48}$ Marko Paşa'nın Nazırlığı dönemde, Kırımlı Aziz Bey’in öncülük ettiği bir "Cemiyet-i Tıbbiye-i Osmaniye" ekolünün oluşumunu görürüz. ${ }^{49}$ Marko Paşa ise, Askeri Tibbiye'nin "Rum ekolü” içinde konumlanabilir. II. Mahmud ve Abdülmecid dönemlerinde Tibbiye muallimleri olan Dr. Stefanos Karatodori (İstefanaki), Dr. Konstantin Karatodori ve Dr. Sarandis Arhiyenis ile başlatabileceğimiz bu öğretim ekolü ; Abdülaziz döneminde Dr. Marko Paşa ile etkinliğini artırmış ve nihayet II. Abdülhamid döneminde Dr. Spiridon Mavroyeni, Dr. Pavlaki Fenerli ve Dr. Aleksandros Zoiros (Çaliki) Paşalarla Mekteb-i Tıbbiye-i Şahane'de güçlü bir söz sahibi olmuştur. ${ }^{50}$ Askeri Tıbbiye'deki "Rum ekolü”nün, içinde yaşanan rekabete karşın, bir 'çıkar grubu' karakteri taşıdığı önerilebilir.

Saygılı \& Okuyucu, Dr. Stefanos Karatodori'nin oğlu Aleksandros Karatodori Paşa'nın “1878'de Berlin Kongresi’nde Osmanlı Devleti'ni temsil ederken gösterdiği gayretin bu dönemdeki Rum aydınların Osmanlı tebaası olmayı nasıl içselleştirdiğinin bir örneği” olarak görmek istemektedirler (s. 27). Ancak, Karatodori Paşa'nın Berlin'den dönüşünde II. Abdülhamid tarafından kabul edilmediği gerçeği yadsınamaz. ${ }^{51}$

Marko Paşa'nın biyografilerinde genişçe bir yer tutan yolsuzluk iddiaları konusundaki soruşturmalar zamanında sonuçlandırılamamış görünmektedir. Döneminin önemli kurumlarından olan Mekteb-i Tıbbiye-i Şahane'nin yönetim, işletme ve denetim sorunlarıyla örneklenen, fakat irdelenmediği için karanlıkta kalan bir yüzü olduğunu söyleyebiliriz.

Marko Paşa efsanesi onun gerçek yaşamının araştırılmasının kapısını açmış ; Kızılay kuruculuğunun kazandırdığg statü içinde Dr. Marko Paşa'nın yaşamı değişik yönleriyle ele alınarak incelenebilmiştir.

Artık derdini anlatma sırası Marko Paşa'da!

48 Özgür Y1lmaz, "Fransız Epidemiyolog Antoine Fauvel'in Osmanlı Devleti'ndeki Çalışmaları (1847-1867)," Uluslararası Katılımlı Osmanlı Bilim ve Düşünce Tarihi Sempozyumu Bildiriler Kitabı, [Gümüşhane,] 0810 Mayls 2014, yay. haz. Mehmet Fatih Gökçek, Orhan Bingöl, M. Ahmet Tüzen (Ankara: Gümüşhane Üniversitesi yay., 2014) içinde, 190-206.

49 Emre Dölen, Türkiye’de Modern Kimyanın Öncülerinden Kırımlı Dr. Aziz Bey (1840-1878). İstanbul: Türkiye Kimya Derneği yay., 2019.

50 Constantinos Trompoukis, John Lascaratos. "Greek professors of the Medical School of Constantinople during a period of reformation (1839-76)," Journal of Medical Biography 11, 4 (Nov. 2003): 226-231.

51 Peri Efe, "Bir Osmanlı Bürokratı: Aleksandır Karatodori Paşa / Millet-i Rum'dan Bir Münevver: Aleksandros Karatheodoris,” Toplumsal Tarih 26, 193 (Ocak 2010): 83-93. Karatodori Paşa’nın adının geçmesi yaklaşık yüz yıl sonra TBMM'nde bir siyasal krize yol açmıştır, bkz. Ali Sirmen, "Kara Todori Kimdir ?," Cumhuriyet, sayı 18257, 29 May1s 1975, s. 3, sü. 7-8. 
